these children have much lower educational performances, even after adjustment for differences in income. ${ }^{5}$ Evidence exists that an absent father is an important factor in teenage suicide, ${ }^{6}$ a phenomenon that has increased by $50 \%$ in Britain in the past 20 years.

The differences between the approaches to social policy in the two groups of countries is profound and becoming more so each year. The failure of the British government to ratify the social chapter of the Maastricht Treaty exemplifies Britain's sense of separateness. Unicef's report shows clearly how children have been among the biggest losers. The fundamental problem is that markets simply do not work for children. Continental Europe clearly recognises the future benefits that the state will derive from having a well educated workforce that can compete internationally and invests in future generations instead of regarding children as a private good whose sole function is to provide emotional satisfaction to parents.

Investing in children is simply enlightened self interest. The Institute of Public Policy Research has shown that investment in high quality, affordable child care would yield a direct rate of return to the government of between $5 \%$ and $51 \%$, depending on uptake, and a rate of return to society as a whole (including enhanced earnings and increased tax revenue) of between $24 \%$ and $84 \% .^{7}$ Child Neglect in Rich
Nations points to New Zealand as an example of the social consequences of failing to invest in children, where the dismantling of the welfare state has been associated with rising crime and an increase in the rate of suicides among young people to one of the highest in the industrialised world. Britain and the United States consistently come at the bottom of international comparisons of educational achievement.

The diversity of policies and outcomes in industrialised countries offers clear lessons for policy makers. Unicef's reports are indictments of the laissez faire policies pursued by the Anglo-American countries. Children are our future. If we fail to invest in them we will be the ultimate losers.

MARTIN McKEE Senior lecturer

London School of Hygiene and Tropical Medicine, London WC1E 7HT

1 Unicef. The progress of nations. New York: Unicef, 1993.

2 Hewlett SA. Child neglect in rich nations. New York: Unicef, 1993.

3 Organisation for Economic Cooperation and Development. Historical statistics 1960-89. Paris: OECD, 1991.

4 Fuchs V. Women's quest for economic equality. Cambridge, MA: Harvard University Press, 1988.

5 Fitzgerald Krein S, Beller AH. Educational attainment of children from single-parent families: differences by exposure, gender and race. Demography 1988;25:221-33.

6 Velez CN, Cohen P. Suicidal behavior in a community sample of children: maternal and youth reports. $¥$ Am Acad Child Adolesc Psychiatry 1988;27:349-56.

7 Cohen B. Fraser N. Childcare in a modern welfare state: towards a new national policy. London: Institute of Public Policy Research, 1991.
.

\title{
Refugee children
}

\section{Need coordinated care}

By the end of the century refugees may number 25 million worldwide, half of them children. ${ }^{1}$ The growth of United Nations agencies, better transport, electronic border controls, and evacuations have greatly altered the "world stage" for refugees. Refugee children continue to arrive in countries that are poorly prepared for them. The time has come to formulate policies on the best ways of providing for these vulnerable children. Last month two meetings organised by interested agencies addressed the topic.

Participants agreed that the quality of life for refugee children would be improved if policies were based on the Geneva Convention of 1949 and its additional protocols (1977) as well as the 1989 UN Convention on the Rights of the Child. ${ }^{1}$ When possible, cooperation should continue between the host country and the country of origin. Some European countries already have comprehensive policies to respond to the needs of refugee children, ${ }^{2}$ and other countries should tap into these.

Host countries should have a policy that encourages the reunification of families, and unaccompanied children should never be presumed to be without living relatives; the International Movement of Red Cross and Red Crescent Societies have wide experience of identifying children and tracing family members.

Despite heroic efforts by local people and professionals, children's needs cannot always be met within a country at war, even though this has long been recognised as the ideal. ${ }^{3-5}$ At the meetings refugee doctors from Bosnia described the horrifying state of anarchy and widespread physical, emotional, and sexual abuse of children in their country, the absence of any truly safe havens, and their despair at the lack of a prospect for peace. Angola has one million displaced children and 2000 children in government homes because both parents and the extended family have been killed or imprisoned or are missing. An extended network of foster care has been set up, which includes teams to screen potential foster parents.

Only when children's needs cannot possibly be met in their own country should they be evacuated, and properly secured safe havens are essential for this. Ideally the evacuation of children should be coordinated by the UN High Commission for Refugees, Unicef, and the International Organisation for Migration (an independent intergovernmental agency) according to careful selection criteria. These should be focused on the needs of children as outlined in the UN convention (1989). ${ }^{1}$ If too restrictive they will encourage "unofficial evacuations."

Protocols for evacuation should ensure that children remain with their families and that siblings remain together. Although non-government organisations may have an important role in evacuating children from war zones, some groups lack appropriate selection criteria, registration and assessment procedures, safe transport, or adequate reception facilities. Whenever possible they should work in partnership with the United Nations High Commission for Refugees and Unicef.

Previously, refugee children have not always received optimal management in host countries. Government departments should therefore have clearly defined policies and designated responsibilities, ideally under one coordinating body. The legal status of refugee children, their security and the duration of that security, and their emotional, psychological, medical, and psychiatric needs must all be addressed. In Britain their management will require the coordination of services provided by the Home Office; the Departments of Health, Environment, and Education; the Refugee Council; the UN High Commission for Refugees; Unicef; and the Red Cross. Language and communication facilities should ideally be arranged before their arrival, and children's educational needs and requirements for health care should be addressed 
from the outset. ${ }^{6-8}$ When appropriate, bereavement counselling should be available.

Unaccompanied children will mainly be placed in foster care or children's homes, particularly if they have learning difficulties, physical handicap, or behavioural or psychiatric disorders. In Britain local authorities will be responsible for identifying, screening, supervising, and supporting foster parents. ${ }^{9}$ Concern was expressed at the meetings about some private fostering and adoption activities. Every attempt should be made to provide a cultural, religious, and ethnic match between foster parents and the children; an absence of these, however, should not exclude otherwise ideal foster parents-as last month's white paper on adoptions counsels. ${ }^{10}$ An adult, ideally of the same nationality, should be appointed for each unaccompanied child at the time of his or her arrival to support their needs throughout their time as a refugee.

The imbalance between the resources provided for refugee children and those for children from deprived families in the host country will provoke debate. In many cases the extreme suffering experienced by many refugee children justifies any imbalance. In addition, attending to the needs of refugee children may bring benefits to other children in the host country-for example, by reviewing and highlighting gaps in services. Finally, and perhaps most importantly, governments need to decide what proportion of the world's refugee children they are willing to accept and to provide for them according to the standards outlined above.

D P SOUTHALL

Academic Department of Paediatrics, Professor of paediatrics

University of Keele,

North Staffordshire Hospital,

Stoke on Trent ST4 6QG

Department of Health Policy and Management,

MARY E BLACK Visiting lecturer

Harvard School of Public Health,

Boston, MA 02120,

USA

1 UN convention on the rights of the child. New York: United Nations, 1991.

2 Ayotte W, Lown J, eds. Children or refugees? A survey of west European policies on unaccompanied refugee children. London: Children's Legal Centre, 1992.

Freud A, Burlingham D. Reactions to evacuations: "war and children." New York: International Universities Press, 1944.

US Committee for Refugees. Bosnian children of war: the adoption question. New York: International Social Service, 1993.

5 Ressler EM. Evacuation of children from conflict areas: consideration and guidelines. Geneva: United Nations High Commissioner for Refugees, Unicef, 1992.

6 Black M, Healing T. Communicable diseases in former Yugoslavia and in refugees arriving in the United Kingdom. Communicable Disease Report 1993;6:R87-90.

7 Hacksound M, ed. Helping children cope with stress of war. Geneva: Unicef, 1993.

8 Williamson J, Moser A. Unaccompanied children in emergencies. A field guide for their care and protection. Geneva: International Social Service, 1987.

9 Home Office, Department of Health, Department of Education and Science, Welsh Office. Working together under the Children's Act 1989. A guide to arrangements for inter-agency cooperation for the protection of children from abuse. London: HMSO, 1991.

10 Dyer C. Political correctness goes in changes to adoption law. BMf 1993;307:1231.

\section{Left handedness}

\section{Reduces the life span for $10 \%$ of the population}

Philosophers have long debated what distinguishes humans from animals-the capacity for language or for rational thought; the use of culture and symbolic exchange; or the use of tools. Stanley Coren's recent book on left handedness came up with a rather novel proposal that "not only have human beings developed a dominant hand, but also they exhibit a species wide preference for the right side as the dominant one. In no other species are these two characteristics, consistent handedness and right sidedness, both present."1

Martin Heidegger is perhaps the only major philosopher to have put forward a similar argument, in his commentaries on Parmenides, when he claimed that no other animals have hands; they may have claws and paws but they do not have the capacity for manual dexterity that is so prominent in humans. ${ }^{2}$ It has been claimed that the capacity to manipulate the object world was essential for the intellectual development of the human brain. Coren's cross cultural research shows that whereas around $90 \%$ of people are right handed only $50 \%$ of monkeys show distinctive right handedness. ${ }^{1}$ In fact, Coren suggests that humans are "the lop-sided animal."

Handedness goes with sidedness; whereas nine out of 10 people are right handed, eight are right footed, seven are right eyed, and six right eared. This distinctive asymmetry in the human population is itself systematic. Perhaps because of the universality of the sidedness, being left handed is definitely unfortunate. Throughout human history, cultural anthropologists have shown, the left side is associated with evil, with weakness, with the female, and with illegitimacy.

The symbolism of the hand was pursued in a brilliant essay by Robert Hertz published in translation as Death and the Right Hand. ${ }^{3}$ Hertz argued that the polarity between right and left is a fundamental expression of a religious dualism between sacred and profane. We find this idea in feudal heraldry, where a stripe on the left side of a shield was referred to as the bend sinister-which was a symbol for illegitimacy and gave an extra meaning to the word sinister.

Coren has collected evidence that left sidedness is related to differences in morbidity and mortality. Left handers are more likely than right handers to suffer from insomnia; people who report allergies are $80 \%$ more likely to be left handed. Left handedness also seems to be associated with certain behavioural problems such as alcoholism and with suicide.

Is right handedness genetically or culturally determined? For many generations strong pressure was applied on children to adopt a right handed preference, and evidence from school histories suggests that children were stigmatised if they persisted in left handed practices. Over the past two decades, however, this stigmatisation has declined, and indeed in North America there has been a movement towards ambidexterity. In the 1980 s the Ambidextral Cultural Society flourished, encouraging ambidexterity as a distinct advantage for children.

Coren has discovered the odd fact that with the aging of populations left handedness declines. Whereas at the age of 10 about $15 \%$ of the population is left handed, beyond the age of 80 less than $1 \%$ is left handed. The decline of left handedness could be explained either by cultural pressure lowering the prevalence of left handedness or by left handed people dying younger. Coren's research suggested that people do not transfer from left to right handedness with age, and he pursued the idea that left handers die younger.

Coren took demographic data on baseball players in the United States from the Baseball Encyclopedia. He found that the average age of death for right handers was about 75 while the average age of death for left handers was 66 . The difference in life.span was a product of differences in birth histories, slower patterns of growth, sleep problems, immunological 